\title{
Evaluation of the efficacy of Ajuga decumbens extract supplement in individuals with knee discomfort associated with physical activity: A randomized, double-blind, placebo-controlled study
}

\author{
YOKO SAWADA ${ }^{1}$, ATSUSHI SUGIMOTO ${ }^{1}$, TAKEHITO HANANOUCHI ${ }^{2}$, NORIMASA SATO $^{3}$ and ISAO NAGAOKA ${ }^{4}$ \\ ${ }^{1}$ Technology Research and Development Laboratory, Research and Development Headquarters, Asahi Group Foods, Ltd., \\ Moriya, Ibaraki 302-0106; ${ }^{2}$ Medical Engineering Laboratory, Department of Mechanical Engineering, Faculty of \\ Engineering, Osaka Sangyo University, Osaka 574-8530; ${ }^{3}$ Umeda Oak Clinic, Osaka 530-0057; ${ }^{4}$ Department of \\ Host Defense and Biochemical Research, Graduate School of Medicine, Juntendo University, Tokyo 113-8421, Japan
}

Received September 28, 2016; Accepted March 6, 2017

DOI: $10.3892 /$ etm.2017.5064

\begin{abstract}
The aim of the present study was to assess the efficacy and safety of the oral administration of Ajuga decumbens extract (ADE) supplement to individuals with knee discomfort associated with physical activity. A randomized, double-blind, placebo-controlled study was conducted using 48 subjects. The subjects were randomly allocated to an ADE diet group (oral administration of ADE-containing diet, $n=24$ ) or a placebo group $(n=24)$, and the intervention was conducted for 12 weeks. A total of 22 subjects in the placebo group and 22 subjects in the ADE diet group were assessed to be eligible for assessment of the efficacy of supplement. Knee function was assessed by changes in the scores of the Japanese Knee Osteoarthritis Measure (JKOM) questionnaire and the scores of the Japan Orthopedic Association (JOA) criteria, as well as by analyzing the levels of type II collagen synthesis and degradation biomarkers (procollagen II C-terminal propeptide, cross-linked C-telopeptide of type II collagen, collagen type II cleavage and matrix metalloproteinase-13). Outcomes were measured at the baseline and at 4, 8 and 12 weeks from the start of administration. Subscale II (joint flexion/stiffness) of the JOA criteria was markedly improved in the ADE diet group compared with the placebo group at 8 and 12 weeks during the intervention. Furthermore, in the subgroup analyses using subjects with mild knee discomfort, subscale II (pain/stiffness) and IV (general activities) scores of JKOM were significantly improved $(\mathrm{P}<0.05)$ and total JKOM score was markedly improved in the ADE diet group compared with
\end{abstract}

Correspondence to: Ms. Yoko Sawada, Technology Research and Development Laboratory, Research and Development Headquarters, Asahi Group Foods, Ltd., 1-1-21 Midori, Moriya, Ibaraki 302-0106, Japan

E-mail: yoko.sawada@asahi-gf.co.jp

Key words: functional food, Ajuga decumbens, joint health, osteoarthritis score, cartilage metabolism, biomarker the placebo group at week 8 of the intervention. No adverse effects were identified for the administration of ADE. In conclusion, these observations suggest that the administration of an ADE-containing diet is safe and improves joint function (flexion and stiffness) and general activity in subjects with mild knee discomfort. Therefore, ADE could be a promising candidate as a functional food that is beneficial to joint health.

\section{Introduction}

Knee osteoarthritis (OA) is characterized by the progressive destruction of articular cartilage and is the leading cause of pain and physical disability in the elderly (1). The early stage of OA limits movement and causes knee discomfort, thereby impairing patients' ability to perform everyday activities and their quality of life (QOL) (1). The prevalence of radiographic knee OA in Japan is increasing and is estimated to affect 30 million Japanese people over the age of 50 (1). According to the treatment guidelines for OA from the Knee Osteoarthritis Research Society International, non-steroidal anti-inflammatory agents, selective cyclooxygenase- 2 inhibitors and acetaminophen are recommended for treatment of OA (2). However, these agents have also been reported to enhance cartilage destruction and promote OA $(3,4)$. Therefore, novel substances with a chondroprotective action have been sought. The current study evaluated Ajuga decumbens (AD) as a candidate that exhibits a protective action on OA. AD is a natural herb and has long been used as a medicine for pain relief in Japan $(5,6)$. Notably, AD has been indicated to have an anti-inflammatory action in a rat arthritis model (7). Furthermore, AD promotes the osteoblastic differentiation of cultured osteoblasts (7) and the repair of articular cartilage and subchondral bone in a cartilage damaged model (8). However, these beneficial effects on the joint have not been studied in humans. In the current study, the effect of orally administered $\mathrm{AD}$ extract (ADE) was evaluated in subjects who experienced knee discomfort associated with physical activity, but did not require clinical treatment. A dietary supplement containing ADE was administered to the subjects, and the effect on the knee joint was evaluated using OA scores, including the 
Japanese Knee Osteoarthritis Measure (JKOM) $(9,10)$ and the Japan Orthopedic Association (JOA) criteria (11). In addition, type II collagen degradation [cross-linked C-telopeptide of type II collagen (CTX-II) and collagen type II cleavage (C2C)] and synthesis [procollagen II C-terminal propeptide (PIICP)] markers and matrix metalloproteinase (MMP)-13 were analyzed to evaluate the effects of ADE on cartilage metabolism. Furthermore, to evaluate the effect of ADE in more detail, subgroup analyses of the subjects with lower levels of knee discomfort [Kellgren-Lawrence (K/L) grades (12) of 0-I and JOA score $>75$ points] were performed.

\section{Materials and methods}

Study design. A prospective, randomized, double-blind, placebo-controlled and parallel-group comparative study was designed to assess the efficacy and safety of a diet supplemented with ADE. The present study was conducted from November 2014-June 2015 and involved one medical clinical service organization center (Umeda Oak Clinic, Osaka, Japan) under the control of one medical investigator in Japan. The protocol was submitted to and approved by the institutional ethics committee of Aisei Hospital Ueno Clinic (Tokyo, Japan) in October 2014 (20141030-2), and the study was conducted in accordance with The Declaration of Helsinki and Ethical Guidelines for Epidemiological Research (recognized by the Japanese Government in 2008). The objective of the present study was explained to all subjects and written informed consent was provided prior to enrollment.

Subject enrollment. Male and female Japanese subjects (aged 40-80; male:female ratio, 65:58) with knee discomfort associated with physical activity but without radiographic evidence of knee osteoarthritis (K/L grades 0-II: Grade 0, $\mathrm{n}=69$; grade $\mathrm{I}, \mathrm{n}=32$, grade $\mathrm{II}, \mathrm{n}=22$ ) were enrolled from the database of volunteers in NEUES Co., Ltd. (Tokyo, Japan). $\mathrm{K} / \mathrm{L}$ classification of 0 means 'definite absence of X-ray changes', I means 'doubtful absence of X-ray changes' and II means 'minimal absence of X-ray changes' (12). The major exclusion criteria were as follows: i) The presence of gout or rheumatoid arthritis that may cause joint pain; ii) suffering from any other injuries that may have required the use of anti-inflammatory or other medications or physiotherapy treatment by an orthopedist; iii) previous surgical treatment of knee joints; iv) routine use of dietary supplements or medicines containing ADE, hyaluronic acid, glucosamine, chondroitin sulfate or collagen peptides, or are rich in calcium; v) requirement to undergo pharmacological treatments during the study period; vi) performing hard exercise; vii) history of osseous or articular diseases within the past year; viii) diagnosis as having malignant tumor, hypertension, heart disease, kidney disease, thyroid disorder or other serious illness that may have required other physiotherapy treatment; ix) pregnancy; x) nursing mothers or women of childbearing potential; xi) participation in another clinical study; and xii) presence of any medical condition judged by the medical investigator to preclude the subject's inclusion in the study.

Study interventions. The subjects were randomized to the ADE diet group and placebo group, and evaluated. The ADE diet was manufactured in the form of a 1.5 -g powder. The ingredients were $10 \mathrm{mg}$ ADE (>1\% 20-hydroxyecdysone), $360 \mathrm{mg}$ dextrin, $25 \mathrm{mg}$ hydroxypropyl methylcellulose, $46 \mathrm{mg}$ cellulose, $9 \mathrm{mg}$ calcium stearate and 1,050 mg palatinose. ADE was purchased from Matsuura Yakugyo Co, Ltd. (Nagoya, Japan). The amount of ADE was $10 \mathrm{mg}$ in the 1.5-g ADE powder. The placebo diet comprised crystalline cellulose, dextrin and caramel pigment instead of ADE. The study supplement was wrapped in a single pack ( $1.5 \mathrm{~g})$ and provided with a wafer, and the subject took the supplement after breakfast once a day with two cups of water for 12 weeks.

Randomization and blinding. Due to the fact that symptoms, especially pain, vary according to gender in arthritis (13), research coordinators created an allocation table for males and females, randomly assigned eligible subjects and granted allocation numbers to test diet. The allocation table was sealed until the end of the study. All research staff and subjects were blinded to the treatment allocation during the test period. Only the statistics experts and data monitoring committee were unblinded, however, they had no contact with subjects. Following the study, the subjects' data were fixed, and the allocation table was made available for reviewing the study information.

Evaluation of efficacy. The outcomes for the evaluation of efficacy were based on the changes in subscale scores of the JOA criteria for osteoarthritic knees; the changes in the subscale scores of the JKOM criteria; the levels of urinary CTX-II and serum C2C as type II collagen degradation biomarkers $(14,15)$; the levels of serum PIICP as a type II collagen synthesis biomarker (16), the levels of serum MMP-13 (17), the ratio of $\mathrm{CTX}-\mathrm{II} / \mathrm{PIICP}$ and the ratio of $\mathrm{C} 2 \mathrm{C} / \mathrm{PIICP}$. These parameters were measured at the baseline and at weeks 4,8 and 12 . Serum and second void of morning urine were collected from the subjects in a fasting state at baseline, weeks 4, 8 and 12 during the intervention. Serum and urine samples were immediately used for routine laboratory tests; sera and urine samples were aliquoted and stored at $-80^{\circ} \mathrm{C}$ until the assays of CTX-II, C2C, PIICP and MMP-13 using their respective ELISA assay kits: CTX-II, Urine CartiLaps EIA (AC-10F1, Immunodiagnostic Systems, Ltd., Tyne \& Wear, UK); C2C, Collagen Type II Cleavage ELISA (60-1001-001; IBEX Technologies, Inc., Montreal, QC, Canada,); PIICP, Enzyme-linked Immunosorbent Assay kit For Procollagen II C-Terminal Propeptide (SEA964Hu; Uscn Life Sciences, Inc., Wuhan, China); and MMP-13, ELISA Kit For Matrix Metalloproteinase 13 (SEA099Hu; Uscn Life Sciences, Inc.). Serum C2C and urinary CTX-II were used as markers for type II collagen degradation, and serum PIICP was used as a marker for type II collagen synthesis. The ratios of C2C/PIICP and CTX-II/PIICP were also analyzed to assess the changes in the balance of type II collagen degradation and synthesis (cartilage metabolism). The concentrations of CTX-II were corrected for urinary creatinine $(\mathrm{Cr})$ and expressed as $\mathrm{ng} / \mathrm{mmol}$ Cr. Serum MMP-13 was also used as a marker for cartilage degradation, because MMP-13 is a collagenase that contributes to cartilage degradation by cleaving type II collagen triple helix (18).

JOA criteria (10) are used by physicians for subjectively evaluating knee OA treatment, based on the following 


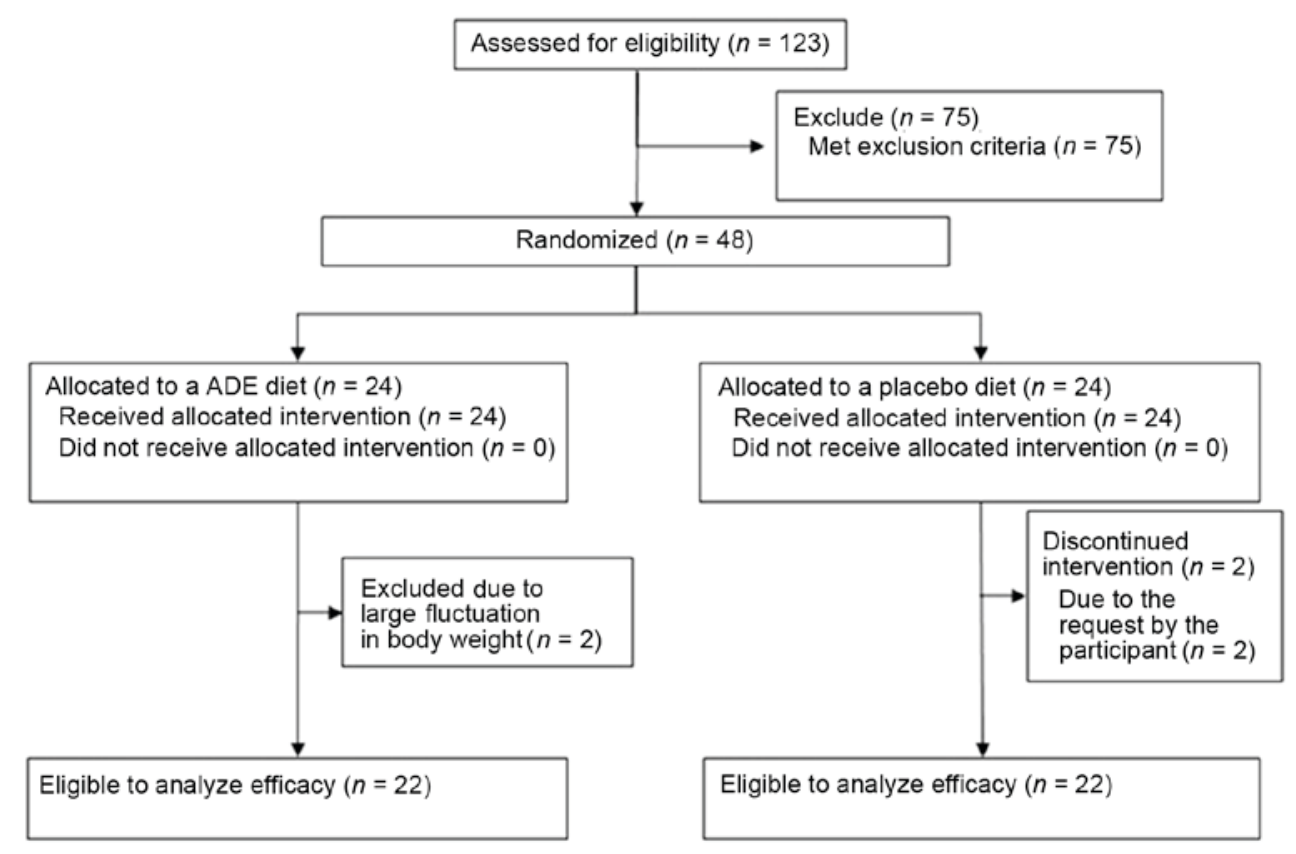

Figure 1. Flow diagram of the participants in the present study. ADE, Ajuga decumbens extract.

subcategories: I) Pain/walking function (rated from 0 to 30); II) pain/step-up and -down function (rated from 0 to 25); III) joint flexion/stiffness (rated from 0-35); IV) swelling (rated from 0-10); and V) aggregated total symptoms. The maximum scores in each subscale indicate no symptoms or functional disability, whereas a score of 0 indicates extreme difficulty in performing daily tasks. The sum of the scores of subscales I-IV represents the score of subscale V (total symptoms score).

The JKOM $(9,10)$ is a self-answered questionnaire that includes five subcategories: I, Pain evaluated by a visual analog scale (VAS); II, pain and stiffness during the past few days (8 questions); III, activities of daily living during the past few days (10 questions); IV, general activities during the past month (5 questions); and V, general health conditions during the past month (2 questions). VAS values range from 0 (no pain) to 100 (pain that cannot be tolerated). The responses to each question (subcategories II-V) are assigned between 1 and 5 points, with 1 point indicating good functional status and 5 points indicating the worst functional status. The JKOM score is higher in subjects with more pain and physical disability, and this evaluation modality is reported to be reliable and valid for studying the clinical outcomes of knee OA (10). The outcome of JKOM has been reported to be closely correlated with that of other arthritis-related scales, such as the Western Ontario and McMaster Universities Arthritis Index and the Medical Outcomes Study 36-Item Short-Form Health Survey (10).

Evaluation of safety. Tolerability and safety were evaluated on the basis of the incidence and severity of dietary supplement-related adverse events reported throughout the study and by changes in physical parameters such as body weight and body mass index (BMI), blood pressure and pulse rates and laboratory test variables, including hematology, blood biochemistry and urinalysis, which were measured by LSI
Medience Corporation (Tokyo, Japan). Each parameter was assessed at 4, 8 and 12 weeks from the start of administration. In addition, throughout the intervention period, changes in physical condition and joints, and use of pharmaceutical products were recorded by subjects in a diary.

Sample size. It was estimated that $\sim 50$ subjects would be necessary to accurately assess the efficacy and safety of ADE, based on a previous study in which a dietary supplement was administered to individuals with knee discomfort who did not require clinical treatment $(19,20)$. To recruit a sufficient number of subjects for analysis, 123 subjects were screened and 48 subjects without any of the exclusion criteria were selected. Due to fluctuations in body weight and requests by the participants, four subjects were excluded from the trial. Finally, 22 subjects in the ADE group and 22 subjects in the placebo group were analyzed (Fig. 1). Furthermore, to evaluate the effect of the test supplement in more detail, the present analysis focused primarily on subjects with mild knee discomfort. Therefore, subjects with $\mathrm{K} / \mathrm{L}$ grades of II and $\leq 75$ points of JOA score were excluded, and the subjects (ADE group, $\mathrm{n}=18$; placebo group, $\mathrm{n}=14$ ) with $\mathrm{K} / \mathrm{L}$ grades of 0 -I and $>75$ points of JOA score were evaluated.

Statistical analysis. All data are expressed as the mean \pm standard deviation unless otherwise specified. The statistical analysis was based on a previous study (20). The baseline characteristics of the entire subject population were compared between the two groups (ADE diet and placebo) using Student's t-test (for continuous variables) and the Mann-Whitney U test (for categorical variables). Changes in the JOA and JKOM scores, and biomarker levels during the intervention were compared with the baseline values using the Student's t-test (for quantitative variables) and the Wilcoxon signed-rank test (for qualitative variables). Comparisons between the two groups were performed using the Student's 
Table I. Baseline characteristics of the study population in the ADE diet and placebo groups.

\begin{tabular}{|c|c|c|c|}
\hline Variable & ADE diet $(n=22)$ & Placebo $(n=22)$ & P-value \\
\hline Age (years) & $51.8 \pm 7.3$ & $53.5 \pm 8.6$ & 0.488 \\
\hline Male:female (n) & $9: 13$ & $10: 12$ & 1.000 \\
\hline Height (cm) & $165.0 \pm 9.2$ & $161.0 \pm 8.4$ & 0.135 \\
\hline Body weight (kg) & $62.6 \pm 9.1$ & $60.3 \pm 10.1$ & 0.426 \\
\hline Body mass index $\left(\mathrm{kg} / \mathrm{m}^{2}\right)$ & $23.0 \pm 2.6$ & $23.2 \pm 3.2$ & 0.747 \\
\hline Body fat mass $(\%)$ & $26.4 \pm 9.2$ & $27.0 \pm 7.25$ & 0.787 \\
\hline Systolic blood pressure (mmHg) & $113.6 \pm 11.3$ & $116.9 \pm 18.1$ & 0.475 \\
\hline Diastolic blood pressure (mmHg) & $72.8 \pm 7.6$ & $75.5 \pm 11.7$ & 0.371 \\
\hline Pulse rate (beats/min) & $68.0 \pm 7.2$ & $71.5 \pm 8.5$ & 0.148 \\
\hline Kellgren-Lawrence grades 0:I:II (n) & $13: 6: 3$ & $10: 6: 6$ & 0.528 \\
\hline Aggregate scores of JOA criteria & $84.8 \pm 8.5$ & $81.8 \pm 9.1$ & 0.235 \\
\hline JKOM (I) VAS score (mm) & $56.4 \pm 16.8$ & $54.1 \pm 14.8$ & 0.636 \\
\hline JKOM (II-V) total score (points) & $47.8 \pm 16.7$ & $46.5 \pm 11.4$ & 0.776 \\
\hline CTX-II (ng/mmol Cr) & $170.4 \pm 106.2$ & $192.8 \pm 100.4$ & 0.488 \\
\hline C2C (ng/ml) & $292.9 \pm 42.9$ & $290.9 \pm 34.0$ & 0.235 \\
\hline PIICP (ng/ml) & $9.3 \pm 2.8$ & $9.7 \pm 3.5$ & 0.636 \\
\hline MMP-13 (ng/ml) & $9.6 \pm 4.0$ & $8.7 \pm 4.3$ & 0.424 \\
\hline
\end{tabular}

All values are expressed as mean \pm standard deviation except where indicated. There were no statistically significant differences between the ADE diet and placebo groups. ADE, Ajuga decumbens extract; JKOM, Japanese Knee Osteoarthritis Measure; VAS, visual analog scale; JOA, Japan Orthopedic Association; CTX-II, cross-linked C-telopeptide of type II collagen; Cr, creatinine; C2C, collagen type II cleavage; PIICP, procollagen II C-terminal propeptide; MMP-13, matrix metalloproteinase-13.

t-test. $\mathrm{P}<0.05$ was considered to indicate a statistically significant difference. Microsoft Excel 2013 (Microsoft Corporation, Redmond, WA, USA) was used for statistical analysis using the t-test, and SPSS 21 software (IBM SPSS, Armonk, NY, USA) was used for other tests.

\section{Results}

Study population. A flow chart of subjects included in the present study is shown in Fig. 1A total of 123 candidates were screened based on K/L grades and JOA score by orthopedists. In addition, a lifestyle questionnaire was administered and body measurements, physical examinations, JKOM assessments and laboratory test variables were performed. The 44 candidates without any of the exclusion criteria were finally selected and randomized to the ADE diet group $(n=22)$ and placebo group $(\mathrm{n}=22)$.

Baseline characteristics in the study population. Table I shows the baseline characteristics of the study population in the ADE diet $(n=22)$ and placebo $(n=22)$ groups. There were no significant differences in any of the baseline characteristics between the ADE diet and placebo groups. The baseline characteristics included demographic characteristics (age and male/female ratio), physiological characteristics (body height, body weight, BMI, systolic blood pressure, diastolic blood pressure and pulse rate), distribution of $\mathrm{K} / \mathrm{L}$ grades, aggregated JOA scores, VAS and total scores of JKOM, and the levels of biomarkers for type II collagen metabolism (CTX-II, C2C, PIICP and MMP-13).
Study population assessment based on JOA subscale scores. Table II shows the changes in the individual subscale and aggregate scores of the JOA criteria in the ADE diet and placebo groups during the 12 -week intervention. In the ADE diet and placebo groups, three subscale scores, I) Pain/walking function, II) Pain/step up and down function and V) Aggregated total symptom scores, were increased relative to the baseline values during the 12 -week intervention (all $\mathrm{P}<0.01$ at 12 weeks, except placebo group subscale II, $\mathrm{P}<0.05$ ). Fig. 2 shows the change in subscale III (joint flexion/stiffness) over the intervention period. The baseline scores were not different between the two groups; however, the score markedly increased in the ADE diet group compared with the placebo group at 8 and 12 weeks $(\mathrm{P}=0.095$ vs. placebo group at both timepoints), suggesting that an ADE-containing diet may improve joint flexion and stiffness.

Study population assessment based on JKOM subscale scores. Table III shows the changes in the five subscale scores of the JKOM responses during the 12-week intervention. In the subscale scores (I-V) and total score, there were no significant differences between the ADE diet and placebo groups at the baseline. Notably, in the ADE diet group, subscale scores I (pain evaluated by VAS) and V (general health conditions) were significantly decreased at 4,8 and 12 weeks compared with the baseline (all $\mathrm{P}<0.01$, except subscale $\mathrm{V}$ at week 4, $\mathrm{P}<0.05)$. Furthermore, in the ADE diet group, subscale score IV (general activity) was significantly decreased at 8 weeks compared with the baseline $(\mathrm{P}<0.05)$, and subscale scores II (pain and stiffness during the past few 
Table II. Individual and aggregate scores of JOA criteria during the intervention period in the ADE diet ( $\mathrm{n}=22)$ and placebo $(n=22)$ groups.

\begin{tabular}{|c|c|c|c|c|c|}
\hline JOA criteria (points) & Group & Baseline & 4 weeks & 8 weeks & 12 weeks \\
\hline \multirow[t]{2}{*}{ I. Pain/walking function } & ADE diet & $21.4 \pm 5.2$ & $25.2 \pm 4.5^{\mathrm{a}}$ & $25.5 \pm 4.3^{\mathrm{a}}$ & $26.4 \pm 3.8^{\mathrm{a}}$ \\
\hline & Placebo & $20.5 \pm 5.3$ & $25.7 \pm 4.4^{\mathrm{a}}$ & $25.9 \pm 2.9^{\mathrm{a}}$ & $28.0 \pm 3.0^{\mathrm{a}}$ \\
\hline \multirow[t]{2}{*}{ II. Pain/step up and down function } & ADE diet & $20.0 \pm 3.5$ & $20.5 \pm 3.4$ & $20.9 \pm 3.7$ & $22.5 \pm 3.0^{\mathrm{a}}$ \\
\hline & Placebo & $19.1 \pm 2.9$ & $21.1 \pm 2.1^{\mathrm{b}}$ & $21.1 \pm 2.1^{\mathrm{b}}$ & $21.8 \pm 2.9^{b}$ \\
\hline \multirow[t]{2}{*}{ III. Joint flexion/stiffness } & ADE diet & $33.4 \pm 3.2$ & $33.6 \pm 3.2$ & $34.5 \pm 2.1$ & $34.5 \pm 2.1$ \\
\hline & Placebo & $32.7 \pm 3.4$ & $33.4 \pm 2.4$ & $33.6 \pm 2.3$ & $33.6 \pm 2.3$ \\
\hline \multirow[t]{2}{*}{ IV. Swelling } & ADE diet & $10.0 \pm 0.0$ & $10.0 \pm 0.0$ & $10.0 \pm 0.0$ & $10.0 \pm 0.0$ \\
\hline & Placebo & $9.5 \pm 1.5$ & $10.0 \pm 0.0$ & $10.0 \pm 0.0$ & $9.8 \pm 1.1$ \\
\hline \multirow[t]{2}{*}{ V. Aggregate total symptoms } & ADE diet & $84.8 \pm 8.5$ & $89.3 \pm 8.2^{\mathrm{a}}$ & $90.9 \pm 8.5^{\mathrm{a}}$ & $93.4 \pm 7.3^{\mathrm{a}}$ \\
\hline & Placebo & $81.8 \pm 9.1$ & $90.2 \pm 6.3^{\mathrm{a}}$ & $90.7 \pm 5.8^{\mathrm{a}}$ & $93.2 \pm 6.5^{\mathrm{b}}$ \\
\hline
\end{tabular}

All values are expressed as mean \pm standard deviation. Changes in the scores during the intervention were compared with the baseline by the Wilcoxon's signed rank test. ${ }^{\mathrm{a}} \mathrm{P}<0.01$ and ${ }^{\mathrm{b}} \mathrm{P}<0.05$ vs. baseline. JOA, Japan Orthopedic Association. ADE, Ajuga decumbens extract.

days), III (activities of daily living during the past few days) and total score were significantly decreased at 8 and 12 weeks compared with the baseline (all $\mathrm{P}<0.01$ except subscale III at week $8, \mathrm{P}<0.05)$. In the placebo group, subscale scores I, II and III and total score were significantly decreased relative to the baseline (all $\mathrm{P}<0.01$ ); however, subscales IV and $\mathrm{V}$ were not significantly changed.

In terms of percentage change from the baseline, subscales II and III and total score were significantly decreased in the placebo and $\mathrm{ADE}$ diet group at 4 weeks following intervention $(\mathrm{P}<0.05$ and $\mathrm{P}<0.01$, respectively). However, subscale scores I, III, IV and V and total score were markedly more decreased in the ADE diet group compared with the placebo group at 8 or 12 weeks following intervention. In particular, the subscales of III, IV and V exhibited a greater decrease in the ADE diet group at 12 weeks compared with the placebo group: $-15.5 \pm 19.8 \%$ in the ADE diet group vs. $-8.9 \pm 56.4 \%$ in the placebo group for subscale III; $-6.8 \pm 20.0 \%$ in the ADE diet group vs. $-0.3 \pm 31.7 \%$ in the placebo group for subscale IV; $-13.6 \pm 28.9 \%$ in the ADE diet group vs. $-3.9 \pm 57.5 \%$ in the placebo group for subscale $\mathrm{V}$.

Study population assessment based on type II collagen metabolism. To evaluate the effect of the ADE diet on type II collagen metabolism, urine and serum samples were used to evaluate levels of cartilage metabolism markers (CTX-II, C2C, PIICP) and a collagenase (MMP-13), as shown in Table IV. CTX-II (a type II collagen degradation marker) was significantly increased relative to the baseline in both the ADE and placebo groups at 8 weeks $(\mathrm{P}<0.05$ and $\mathrm{P}<0.01$, respectively), whereas $\mathrm{C} 2 \mathrm{C}$ (another type II collagen degradation marker) was not significantly changed during the intervention period. PIICP (a type II collagen synthesis marker) was significantly increased compared with the baseline in both groups at 4,8 and 12 weeks (all $\mathrm{P}<0.01$ except ADE diet group at 12 weeks, $\mathrm{P}<0.05)$. Notably, PIICP was markedly increased at 8 weeks in the ADE diet group compared with the placebo group (Fig. 3A; $\mathrm{P}=0.062$ vs. placebo group), suggesting that an

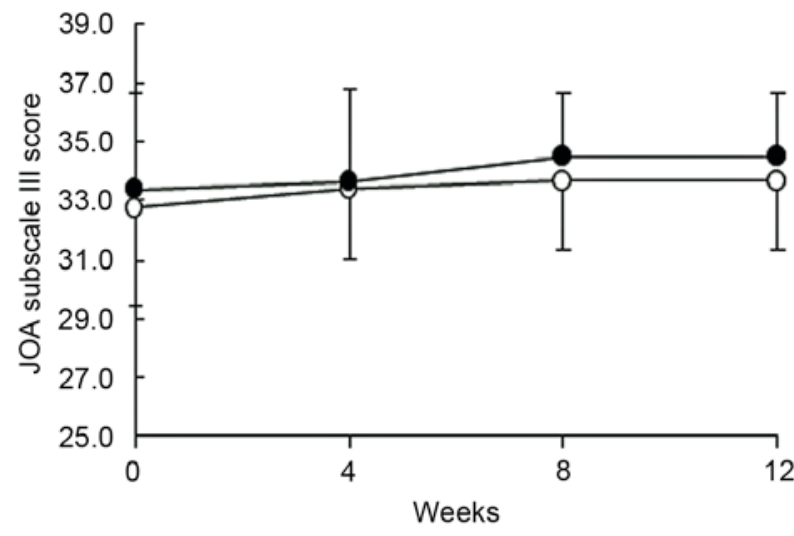

Figure 2. Changes in subscale III of JOA score. Subscale III (joint flexion/stiffness) scores of the JOA criteria were recorded during the intervention in the Ajuga decumbens extract diet (black circles) and placebo groups (white circles). JOA, Japan Orthopedic Association.

ADE-containing diet may enhance type II collagen synthesis. Furthermore, MMP-13 was significantly reduced at 8 and 12 weeks in both groups relative to the baseline (Fig. 3B; $\mathrm{P}<0.01)$.

To further determine the balance of type II collagen metabolism (degradation and synthesis), the ratios of CTX-II and $\mathrm{C} 2 \mathrm{C}$ to PIICP was evaluated. In the ADE diet group, the CTX-II/PIICP ratio was significantly reduced at weeks 4 and $8(\mathrm{P}<0.05$ and $\mathrm{P}<0.01$, respectively), and $\mathrm{C} 2 \mathrm{C} / \mathrm{PIICP}$ ratio was significantly reduced at week 4 relative to the baseline $(\mathrm{P}<0.05)$. Conversely, the $\mathrm{C} 2 \mathrm{C} / \mathrm{PIICP}$ ratio was not significantly changed in the placebo group, although the CTX-II/PIICP ratio was significantly reduced at 4,8 and 12 weeks relative to the baseline in this group $(\mathrm{P}<0.05$, $\mathrm{P}<0.01$ and $\mathrm{P}<0.05$, respectively).

Baseline characteristics for subgroup analysis. To determine the ADE effect on subjects with mild knee discomfort, the subjects with lower K/L grades (0-I) and higher JOA score 
Table III. Changes in the individual and total scores of JKOM response during the intervention period in the ADE diet $(\mathrm{n}=22)$ and placebo $(\mathrm{n}=22)$ groups.

\begin{tabular}{|c|c|c|c|c|c|}
\hline JKOM criteria & Group & Baseline & 4 weeks & 8 weeks & 12 weeks \\
\hline \multirow[t]{2}{*}{ I: VAS score, mm } & ADE diet & $56.4 \pm 16.8$ & $\begin{array}{r}35.5 \pm 24.0^{\mathrm{b}} \\
(-36.9 \pm 38.3)\end{array}$ & $\begin{array}{r}25.5 \pm 21.2^{\mathrm{b}} \\
(-53.5 \pm 36.8)\end{array}$ & $\begin{array}{r}19.5 \pm 18.5^{\mathrm{b}} \\
\left(-64.9 \pm 31.8^{\mathrm{b}}\right)\end{array}$ \\
\hline & Placebo & $54.1 \pm 14.8$ & $\begin{array}{r}26.2 \pm 19.2^{\mathrm{b}} \\
(-51.2 \pm 33.1)\end{array}$ & $\begin{array}{r}25.1 \pm 18.1^{\mathrm{b}} \\
(-53.0 \pm 30.8)\end{array}$ & $\begin{array}{r}18.3 \pm 23.0^{b} \\
\left(-62.5 \pm 47.6^{b}\right)\end{array}$ \\
\hline \multirow[t]{2}{*}{$\begin{array}{l}\text { II: Pain and stiffness } \\
\text { in the knees, points }\end{array}$} & ADE diet & $17.5 \pm 5.9$ & $\begin{array}{l}16.1 \pm 6.8 \\
\left(-8.1 \pm 18.0^{c}\right)\end{array}$ & $\begin{array}{c}14.0 \pm 6.5^{\mathrm{b}} \\
(-20.3 \pm 18.0)\end{array}$ & $\begin{array}{c}13.0 \pm 6.3^{b} \\
(-26.5 \pm 16.9)\end{array}$ \\
\hline & Placebo & $18.3 \pm 4.6$ & $\begin{array}{c}13.6 \pm 3.4^{\mathrm{b}} \\
(-22.8 \pm 22.2)\end{array}$ & $\begin{array}{c}13.7 \pm 3.8^{\mathrm{b}} \\
(-21.6 \pm 26.0)\end{array}$ & $\begin{array}{c}13.1 \pm 6.2^{\mathrm{b}} \\
(-26.9 \pm 31.2)\end{array}$ \\
\hline \multirow[t]{2}{*}{$\begin{array}{l}\text { III: Condition in } \\
\text { daily life, points }\end{array}$} & ADE diet & $16.4 \pm 6.7$ & $\begin{array}{l}16.1 \pm 7.8 \\
\left(-1.5 \pm 19.0^{\mathrm{d}}\right)\end{array}$ & $\begin{array}{c}14.1 \pm 6.2^{\mathrm{a}} \\
(-11.9 \pm 17.2)\end{array}$ & $\begin{array}{c}13.3 \pm 6.0^{\mathrm{b}} \\
(-15.5 \pm 19.8)\end{array}$ \\
\hline & Placebo & $15.6 \pm 4.5$ & $\begin{array}{c}12.5 \pm 2.8^{b} \\
(-15.8 \pm 25.8)\end{array}$ & $\begin{array}{c}12.5 \pm 3.1^{\mathrm{b}} \\
(-17.3 \pm 18.1)\end{array}$ & $\begin{array}{l}13.2 \pm 6.0^{\mathrm{b}} \\
(-8.9 \pm 56.4)\end{array}$ \\
\hline \multirow[t]{2}{*}{$\begin{array}{l}\text { IV: General activities, } \\
\text { points }\end{array}$} & ADE diet & $9.7 \pm 3.5$ & $\begin{array}{c}9.3 \pm 3.9 \\
(-3.5 \pm 21.2)\end{array}$ & $\begin{array}{c}8.5 \pm 3.7^{\mathrm{a}} \\
(-11.6 \pm 22.9)\end{array}$ & $\begin{array}{c}8.9 \pm 3.4 \\
(-6.8 \pm 20.0)\end{array}$ \\
\hline & Placebo & $8.7 \pm 2.3$ & $\begin{array}{c}8.2 \pm 1.8 \\
(-1.7 \pm 23.1)\end{array}$ & $\begin{array}{c}8.2 \pm 1.7 \\
(-0.9 \pm 26.9)\end{array}$ & $\begin{array}{c}8.1 \pm 1.4 \\
(-0.3 \pm 31.7)\end{array}$ \\
\hline \multirow[t]{2}{*}{$\begin{array}{l}\text { V: Health conditions, } \\
\text { points }\end{array}$} & ADE diet & $4.2 \pm 1.8$ & $\begin{array}{c}3.5 \pm 1.3^{\mathrm{a}} \\
(-10.9 \pm 27.0)\end{array}$ & $\begin{array}{c}3.2 \pm 1.1^{\mathrm{b}} \\
(-16.6 \pm 29.1)\end{array}$ & $\begin{array}{c}3.4 \pm 1.4^{\mathrm{b}} \\
(-13.6 \pm 28.9)\end{array}$ \\
\hline & Placebo & $4.0 \pm 1.7$ & $\begin{array}{l}3.5 \pm 1.2 \\
(0.9 \pm 49.5)\end{array}$ & $\begin{array}{c}3.4 \pm 1.1 \\
(-5.1 \pm 37.0)\end{array}$ & $\begin{array}{c}3.3 \pm 1.3 \\
(-3.9 \pm 57.5)\end{array}$ \\
\hline \multirow[t]{2}{*}{ Total score } & ADE diet & $47.8 \pm 16.7$ & $\begin{array}{l}45.0 \pm 18.1 \\
\left(-5.9 \pm 14.4^{\mathrm{d}}\right)\end{array}$ & $\begin{array}{r}39.8 \pm 16.0^{\mathrm{b}} \\
(-15.8 \pm 15.9)\end{array}$ & $\begin{array}{r}38.6 \pm 16.0^{\mathrm{b}} \\
(-18.2 \pm 15.7)\end{array}$ \\
\hline & Placebo & $46.5 \pm 11.4$ & $\begin{array}{c}37.8 \pm 7.5^{\mathrm{b}} \\
(-16.4 \pm 17.6)\end{array}$ & $\begin{array}{c}37.8 \pm 7.6^{\mathrm{b}} \\
(-16.2 \pm 17.7)\end{array}$ & $\begin{array}{r}37.7 \pm 12.8^{\mathrm{b}} \\
(-15.8 \pm 31.4)\end{array}$ \\
\hline
\end{tabular}

All values are expressed as mean \pm standard deviation. The score in the parentheses shows the percentage changes from the baseline. Changes in the scores during the intervention were compared with the baseline by the Wilcoxon's signed rank test. ${ }^{a} \mathrm{P}<0.05$, ${ }^{\mathrm{b}} \mathrm{P}<0.01 \mathrm{vs}$. baseline. The Mann-Whitney U test was used to compare the groups. ${ }^{c} \mathrm{P}<0.05,{ }^{\mathrm{d}} \mathrm{P}<0.01$ vs. placebo group. ADE, Ajuga decumbens extract; JKOM, Japanese Knee Osteoarthritis Measure.

Table IV. Levels of biomarkers for CII metabolism and the ratio of CII destruction to synthesis during the intervention period in the ADE diet $(\mathrm{n}=22)$ and placebo $(\mathrm{n}=22)$ groups.

\begin{tabular}{|c|c|c|c|c|c|}
\hline Variable & Group & Baseline & 4 weeks & 8 weeks & 12 weeks \\
\hline \multirow[t]{2}{*}{ CTX-II (ng/mmol Cr) } & ADE diet & $170.4 \pm 106.2$ & $156.2 \pm 59.2$ & $222.8 \pm 107.1^{\mathrm{a}}$ & $203.8 \pm 85.8$ \\
\hline & Placebo & $192.8 \pm 100.4$ & $180.6 \pm 147.9$ & $274.2 \pm 172.6^{b}$ & $236.0 \pm 152.8$ \\
\hline \multirow[t]{2}{*}{$\mathrm{C} 2 \mathrm{C}(\mathrm{ng} / \mathrm{ml})$} & ADE diet & $292.8 \pm 42.9$ & $293.2 \pm 39.1$ & $286.9 \pm 55.4$ & $295.6 \pm 38.1$ \\
\hline & Placebo & $290.9 \pm 34.0$ & $283.8 \pm 30.5$ & $283.8 \pm 33.2$ & $294.0 \pm 46.4$ \\
\hline \multirow[t]{2}{*}{ PIICP (ng/ml) } & ADE diet & $9.3 \pm 2.8$ & $18.0 \pm 9.5^{\mathrm{b}}$ & $26.0 \pm 12.8^{b}$ & $11.4 \pm 4.7^{\mathrm{a}}$ \\
\hline & Placebo & $9.7 \pm 3.5$ & $15.6 \pm 9.2^{\mathrm{b}}$ & $19.6 \pm 9.1^{b}$ & $12.5 \pm 4.1^{\mathrm{b}}$ \\
\hline \multirow[t]{2}{*}{ MMP-13 (ng/ml) } & ADE diet & $9.6 \pm 4.0$ & $9.6 \pm 4.0$ & $5.9 \pm 3.6^{\mathrm{b}}$ & $5.6 \pm 2.9^{\mathrm{b}}$ \\
\hline & Placebo & $8.7 \pm 4.3$ & $9.2 \pm 4.2$ & $5.5 \pm 3.4^{\mathrm{b}}$ & $5.1 \pm 3.3^{\mathrm{b}}$ \\
\hline \multirow[t]{2}{*}{ CTX-II/PIICP } & ADE diet & $37.2 \pm 26.2$ & $20.9 \pm 10.4^{\mathrm{a}}$ & $14.6 \pm 9.5^{\mathrm{b}}$ & $29.3 \pm 10.5$ \\
\hline & Placebo & $38.2 \pm 28.5$ & $24.4 \pm 12.1^{\mathrm{a}}$ & $17.8 \pm 8.3^{\mathrm{b}}$ & $26.2 \pm 9.2^{\mathrm{a}}$ \\
\hline \multirow[t]{2}{*}{ C2C/PIICP } & ADE diet & $23.0 \pm 24.1$ & $11.4 \pm 7.6^{\mathrm{a}}$ & $12.6 \pm 15.4$ & $19.8 \pm 9.4$ \\
\hline & Placebo & $29.5 \pm 37.1$ & $17.9 \pm 18.7$ & $17.8 \pm 16.1$ & $21.1 \pm 15.1$ \\
\hline
\end{tabular}

All values are expressed as mean \pm standard deviation. Changes in the values during the intervention were compared with the baseline by the Student's t-test. ${ }^{\mathrm{a}} \mathrm{P}<0.05,{ }^{\mathrm{b}} \mathrm{P}<0.01$ vs. baseline. ADE, Ajuga decumbens extract; CII, type II collagen; CTX-II, cross-linked C-telopeptide of type II collagen; Cr, creatinine; C2C, collagen type II cleavage; PIICP, procollagen II C-terminal propeptide; MMP-13, matrix metalloproteinase-13. 
Table V. Baseline characteristics of the subgroup participants with mild knee pain in the ADE diet and placebo groups.

\begin{tabular}{|c|c|c|c|}
\hline Variable & ADE diet $(n=18)$ & Placebo $(n=14)$ & P-value \\
\hline Age (years) & $51.4 \pm 7.1$ & $54.1 \pm 7.2$ & 0.311 \\
\hline Male:female (n) & $7: 11$ & $8: 6$ & 0.476 \\
\hline Height (cm) & $164.5 \pm 9.4$ & $162.3 \pm 8.7$ & 0.511 \\
\hline Body weight (kg) & $62.1 \pm 8.5$ & $59.4 \pm 9.3$ & 0.400 \\
\hline Body mass index $\left(\mathrm{kg} / \mathrm{m}^{2}\right)$ & $22.9 \pm 2.6$ & $22.5 \pm 2.4$ & 0.601 \\
\hline Body fat mass $(\%)$ & $27.4 \pm 7.9$ & $22.3 \pm 8.2$ & 0.164 \\
\hline Systolic blood pressure (mmHg) & $111.6 \pm 11.3$ & $116.0 \pm 16.7$ & 0.389 \\
\hline Diastolic blood pressure (mmHg) & $71.5 \pm 7.3$ & $74.43 \pm 8.2$ & 0.295 \\
\hline Pulse rate (beats/min) & $68.4 \pm 7.5$ & $70.5 \pm 8.3$ & 0.460 \\
\hline Kellgren-Lawrence grades, 0:I:II (n) & 12:6:0 & $8: 6: 0$ & 0.718 \\
\hline Aggregate scores of JOA criteria & $86.4 \pm 7.0$ & $85.0 \pm 5.5$ & 0.363 \\
\hline JKOM (I) VAS score (mm) & $53.1 \pm 15.2$ & $59.0 \pm 13.7$ & 0.265 \\
\hline JKOM (II-V) total score (points) & $42.1 \pm 9.7$ & $43.5 \pm 9.7$ & 0.554 \\
\hline CTX-II (ng/mmol Cr) & $166.2 \pm 110.8$ & $169.6 \pm 86.2$ & 0.924 \\
\hline $\mathrm{C} 2 \mathrm{C}(\mathrm{ng} / \mathrm{ml})$ & $286.2 \pm 43.3$ & $286.1 \pm 26.9$ & 0.998 \\
\hline PIICP (ng/ml) & $9.8 \pm 2.2$ & $9.0 \pm 3.8$ & 0.463 \\
\hline MMP-13 (ng/ml) & $9.5 \pm 4.1$ & $8.4 \pm 4.5$ & 0.463 \\
\hline
\end{tabular}

All values are expressed as mean \pm standard deviation except where indicated. There were no statistically significant differences between the ADE diet and placebo groups. ADE, Ajuga decumbens extract; JKOM, Japanese Knee Osteoarthritis Measure; VAS, visual analog scale; JOA, Japan Orthopedic Association; CTX-II, cross-linked C-telopeptide of type II collagen; C2C, collagen type II cleavage; PIICP, procollagen II C-terminal propeptide; MMP-13, matrix metalloproteinase-13.

A

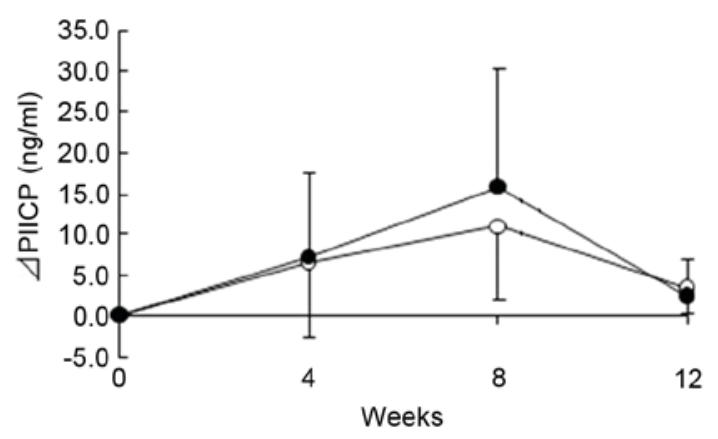

B

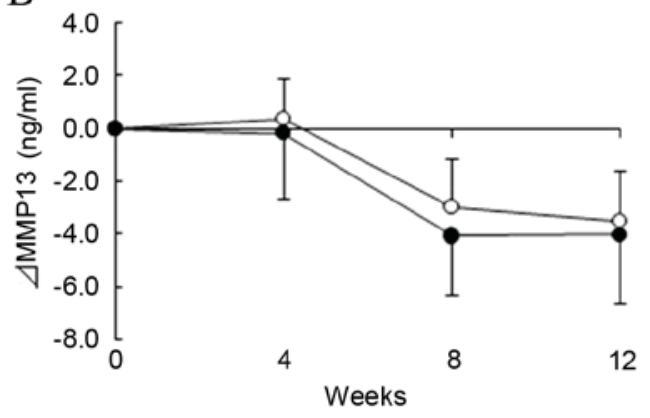

Figure 3. Changes in the levels of serum PIICP and MMP-13. Levels of (A) PIICP and (B) serum MMP-13 from the baseline were recorded during the intervention in the Ajuga decumbens extract diet (black circles) and placebo groups (white circles). PIICP, procollagen II C-terminal propeptide; MMP-13, matrix metalloproteinase-13.

$(>75)$ were selected, and the subgroup analysis was performed. The baseline data are shown in Table V. The ADE diet and placebo groups contained 18 and 14 subjects, respectively. There were no significant differences in any of the baseline characteristics between the two groups.

Subgroup assessment based on JOA subscale score. The JOA subscales for the subgroup analysis are shown in Table VI. In the ADE diet and placebo groups, subscale scores I and V were significantly increased at 4,8 and 12 weeks $(\mathrm{P}<0.01)$, and the subscale II score was significantly increased at 12 weeks relative to the baseline $(\mathrm{P}<0.01$ in $\mathrm{ADE}$ diet group, $\mathrm{P}<0.05$ in placebo group). However, there were no significant differences in these subscale scores between the two groups. Notably, subscale III was markedly increased and reached the maximum score (35 points, indicating no symptoms) at weeks 8 and 12 in the ADE diet group, whereas the subscale score only increased minimally in the placebo group.

Subgroup assessment based on JKOM subscale scores. Table VII shows the JKOM subscale scores for the subgroup during the 12-week intervention. In the ADE diet group, subscale scores (I-V) and total score decreased relative to the baseline at 8 or 12 weeks (all $\mathrm{P}<0.01$, except subscales IV and V, $\mathrm{P}<0.05)$. Furthermore, subscale scores II and IV significantly decreased in the ADE diet group compared with the placebo 
Table VI. Individual scores and aggregate scores of JOA criteria during the intervention period for subgroup participants with mild knee pain in the ADE diet $(n=18)$ and placebo $(n=14)$ groups.

\begin{tabular}{|c|c|c|c|c|c|}
\hline JOA criteria (points) & Group & Baseline & 4 weeks & 8 weeks & 12 weeks \\
\hline \multirow[t]{2}{*}{ I. Pain/walking function } & ADE diet & $22.5 \pm 4.6$ & $26.1 \pm 4.0^{\mathrm{a}}$ & $26.7 \pm 3.4^{\mathrm{a}}$ & $27.5 \pm 3.1^{\mathrm{a}}$ \\
\hline & Placebo & $21.8 \pm 4.6$ & $25.4 \pm 5.0^{\mathrm{a}}$ & $26.4 \pm 2.3^{\mathrm{a}}$ & $28.9 \pm 2.1^{\mathrm{a}}$ \\
\hline \multirow[t]{2}{*}{ II. Pain/step up and down function } & ADE diet & $20.3 \pm 3.6$ & $20.8 \pm 3.5$ & $21.4 \pm 3.8$ & $23.1 \pm 3.0^{\mathrm{a}}$ \\
\hline & Placebo & $19.3 \pm 2.7$ & $20.7 \pm 1.8$ & $21.4 \pm 2.3$ & $22.1 \pm 2.6^{b}$ \\
\hline \multirow[t]{2}{*}{ III. Joint flexion/stiffness } & ADE diet & $33.6 \pm 2.9$ & $33.9 \pm 2.7$ & $35.0 \pm 0.0$ & $35.0 \pm 0.0$ \\
\hline & Placebo & $33.9 \pm 2.1$ & $33.9 \pm 2.1$ & $34.3 \pm 1.8$ & $34.3 \pm 1.8$ \\
\hline \multirow[t]{2}{*}{ IV. Swelling } & ADE diet & $10.0 \pm 0.0$ & $10.0 \pm 0.0$ & $10.0 \pm 0.0$ & $10.0 \pm 0.0$ \\
\hline & Placebo & $10.0 \pm 0.0$ & $10.0 \pm 0.0$ & $10.0 \pm 0.0$ & $10.0 \pm 0.0$ \\
\hline \multirow[t]{2}{*}{ V. Aggregate total symptoms } & ADE diet & $86.4 \pm 7.9$ & $90.8 \pm 6.7^{\mathrm{a}}$ & $93.1 \pm 6.4^{\mathrm{a}}$ & $95.6 \pm 5.7^{\mathrm{a}}$ \\
\hline & Placebo & $85.0 \pm 5.5$ & $90.0 \pm 6.5^{\mathrm{a}}$ & $92.1 \pm 4.7^{\mathrm{a}}$ & $95.4 \pm 5.0^{\mathrm{a}}$ \\
\hline
\end{tabular}

All values are expressed as mean \pm standard deviation. Changes in the scores during the intervention were compared with the baseline by the Wilcoxon's signed rank test. ${ }^{\mathrm{a}} \mathrm{P}<0.01,{ }^{\mathrm{b}} \mathrm{P}<0.05$ vs. baseline. JOA, Japan Orthopedic Association. ADE, Ajuga decumbens extract.

Table VII. Individual and total scores of JKOM response during the intervention for subgroup participants with mild knee pain in the $\operatorname{ADE}$ diet $(n=18)$ and placebo $(n=14)$ groups.

\begin{tabular}{|c|c|c|c|c|c|}
\hline JKOM criteria & Group & Baseline & 4 weeks & 8 weeks & 12 weeks \\
\hline \multirow[t]{2}{*}{$\mathrm{I}: \mathrm{VAS}, \mathrm{mm}$} & ADE diet & $53.1 \pm 15.2$ & $\begin{array}{c}28.3 \pm 19.0^{\mathrm{b}} \\
\left(-44.9 \pm 35.5^{\mathrm{b}}\right)\end{array}$ & $\begin{array}{c}19.3 \pm 17.8^{b} \\
\left(-60.0 \pm 37.4^{b}\right)\end{array}$ & $\begin{array}{c}14.1 \pm 13.7^{\mathrm{b}} \\
\left(-71.9 \pm 28.1^{\mathrm{b}}\right)\end{array}$ \\
\hline & Placebo & $60.4 \pm 12.8$ & $\begin{array}{c}31.5 \pm 20.5^{b} \\
\left(-47.7 \pm 30.1^{b}\right)\end{array}$ & $\begin{array}{c}25.1 \pm 20.9^{b} \\
\left(-57.4 \pm 34.9^{b}\right)\end{array}$ & $\begin{array}{c}13.2 \pm 17.0^{\mathrm{b}} \\
\left(-74.7 \pm 71.9^{\mathrm{b}}\right)\end{array}$ \\
\hline \multirow[t]{2}{*}{$\begin{array}{l}\text { II: Pain and stiffness } \\
\text { in the knees, points }\end{array}$} & ADE diet & $15.4 \pm 3.8$ & $\begin{array}{l}13.7 \pm 3.8^{a} \\
\left(-9.7 \pm 18.0^{a}\right)\end{array}$ & $\begin{array}{c}11.6 \pm 3.6^{b, c} \\
\left(-23.4 \pm 17.2^{b}\right)\end{array}$ & $\begin{array}{c}10.4 \pm 2.4^{b} \\
\left(-30.7 \pm 12.3^{b}\right)\end{array}$ \\
\hline & Placebo & $17.1 \pm 4.3$ & $\begin{array}{c}13.5 \pm 2.9^{b} \\
\left(-17.2 \pm 24.5^{b}\right)\end{array}$ & $\begin{array}{c}13.4 \pm 3.2^{\mathrm{a}} \\
\left(-16.9 \pm 29.5^{\mathrm{a}}\right)\end{array}$ & $\begin{array}{c}11.4 \pm 4.1^{\mathrm{a}} \\
\left(-31.1 \pm 21.9^{\mathrm{b}}\right)\end{array}$ \\
\hline \multirow[t]{2}{*}{$\begin{array}{l}\text { III: Condition in daily } \\
\text { life, points }\end{array}$} & ADE diet & $14.2 \pm 4.3$ & $\begin{array}{l}13.6 \pm 4.5 \\
(-2.8 \pm 19.7)\end{array}$ & $\begin{array}{c}12.1 \pm 3.4^{b} \\
\left(-12.3 \pm 15.4^{b}\right)\end{array}$ & $\begin{array}{c}11.2 \pm 1.5^{b} \\
\left(-16.7 \pm 16.7^{b}\right)\end{array}$ \\
\hline & Placebo & $14.1 \pm 3.7$ & $\begin{array}{l}12.6 \pm 2.8 \\
(-7.1 \pm 27.7)\end{array}$ & $\begin{array}{c}11.6 \pm 2.1^{\mathrm{a}} \\
\left(-14.3 \pm 19.5^{\mathrm{a}}\right)\end{array}$ & $\begin{array}{l}12.8 \pm 6.8 \\
(-2.5 \pm 67.8)\end{array}$ \\
\hline \multirow[t]{2}{*}{$\begin{array}{l}\text { IV: General activities, } \\
\text { points }\end{array}$} & ADE diet & $8.7 \pm 1.6$ & $\begin{array}{c}8.2 \pm 1.4 \\
(-2.9 \pm 21.1)\end{array}$ & $\begin{array}{c}7.3 \pm 1.3^{\mathrm{a}, \mathrm{c}} \\
\left(-12.6 \pm 24.2^{\mathrm{a}}\right)\end{array}$ & $\begin{array}{c}7.8 \pm 1.2 \\
(-7.0 \pm 20.9)\end{array}$ \\
\hline & Placebo & $8.6 \pm 2.2$ & $\begin{array}{c}8.2 \pm 1.8 \\
(-2.2 \pm 20.1)\end{array}$ & $\begin{array}{c}8.6 \pm 1.5 \\
(4.0 \pm 28.9)\end{array}$ & $\begin{array}{c}8.1 \pm 1.3 \\
(-0.3 \pm 31.0)\end{array}$ \\
\hline \multirow[t]{2}{*}{$\begin{array}{l}\mathrm{V} \text { : Health conditions, } \\
\text { points }\end{array}$} & ADE diet & $3.8 \pm 1.5$ & $\begin{array}{c}3.3 \pm 0.8 \\
(-8.1 \pm 26.5)\end{array}$ & $\begin{array}{c}3.0 \pm 0.8^{a} \\
(-13.7 \pm 31.3)\end{array}$ & $\begin{array}{c}3.1 \pm 0.8^{a} \\
(-12.3 \pm 31.3)\end{array}$ \\
\hline & Placebo & $3.5 \pm 1.3$ & $\begin{array}{c}3.6 \pm 1.3 \\
(10.4 \pm 55.5)\end{array}$ & $\begin{array}{c}3.4 \pm 1.3 \\
(0.5 \pm 40.9)\end{array}$ & $\begin{array}{c}3.3 \pm 1.3 \\
(3.3 \pm 66.6)\end{array}$ \\
\hline \multirow[t]{2}{*}{ Total score } & ADE diet & $42.1 \pm 9.7$ & $\begin{array}{l}38.8 \pm 9.4 \\
(-6.7 \pm 15.2)\end{array}$ & $\begin{array}{c}34.0 \pm 7.2^{\mathrm{b}} \\
\left(-17.2 \pm 15.8^{\mathrm{b}}\right)\end{array}$ & $\begin{array}{c}32.5 \pm 4.0^{\mathrm{b}} \\
\left(-20.3 \pm 13.1^{\mathrm{b}}\right)\end{array}$ \\
\hline & Placebo & $43.8 \pm 9.7$ & $\begin{array}{c}37.7 \pm 7.2^{\mathrm{a}} \\
\left(-10.8 \pm 17.8^{\mathrm{a}}\right)\end{array}$ & $\begin{array}{c}36.5 \pm 5.7^{\mathrm{a}} \\
\left(-12.3 \pm 18.6^{\mathrm{a}}\right)\end{array}$ & $\begin{array}{r}35.9 \pm 11.9^{a} \\
(-15.3 \pm 31.4)\end{array}$ \\
\hline
\end{tabular}

All values are expressed as mean \pm standard deviation. The score in the parentheses shows the percentage changes from the baseline. Changes in the scores during the intervention were compared with the baseline by the Wilcoxon's signed rank test. ${ }^{\mathrm{a}} \mathrm{P}<0.05$, ${ }^{\mathrm{b}} \mathrm{P}<0.01$. The Mann-Whitney $\mathrm{U}$-test was used to compare the groups. ${ }^{\mathrm{c}} \mathrm{P}<0.05$ vs. placebo group.

group at 8 weeks (Fig. $4 \mathrm{~A}$ and $\mathrm{B} ; \mathrm{P}<0.05$ ). Total score was markedly decreased in the ADE diet group compared with the placebo group at 8 weeks (Fig. 4C). Furthermore, in terms of percentage change from the baseline, the subscale scores I, II, 
A

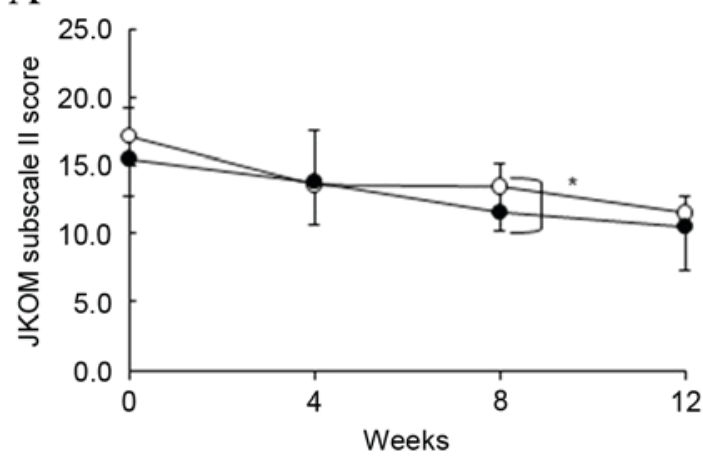

C

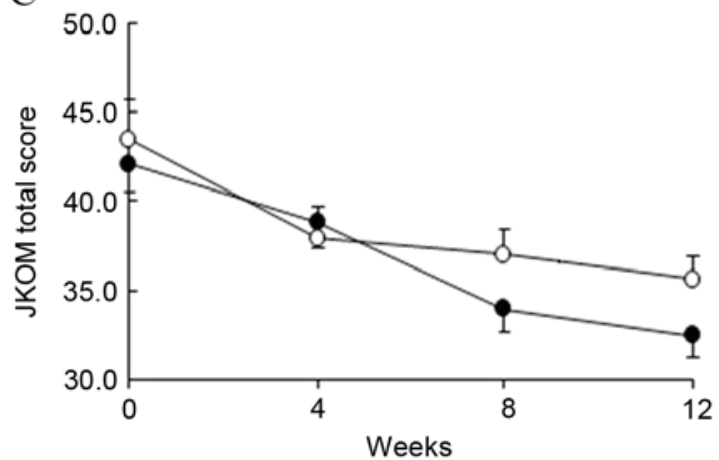

B

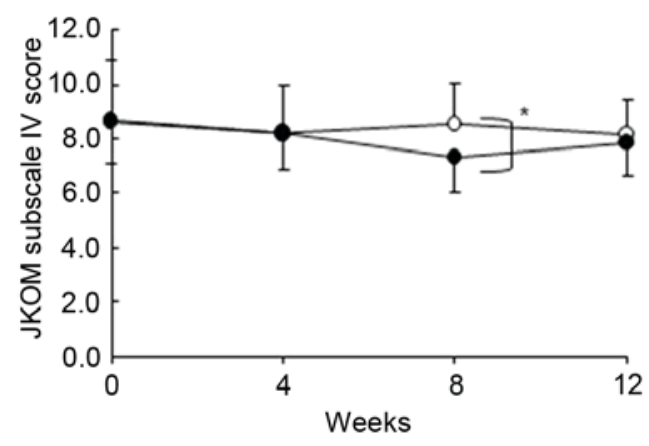

Figure 4. Changes in subscales II and IV, and total score of JKOM response criteria for subgroup analysis (mild knee pain). The three subscales of JKOM response criteria, (A) II (pain and stiffness in the knees), (B) IV (general activities) and (C) total score were recorded during the intervention in the Ajuga decumbens extract diet (black circles) and placebo groups (white circles). $\mathrm{P}<0.05$. JKOM, Japanese Knee Osteoarthritis Measure.

IV and $\mathrm{V}$ and total score exhibited a greater decrease in the ADE diet group compared with the placebo group at 8 weeks (Table VII).

Safety assessment. The safety of 48 subjects allocated to the ADE diet and placebo groups was evaluated. A total of 11 $(45.8 \%)$ subjects in the placebo group $(n=24)$ and $13(54.2 \%)$ subjects in the ADE diet group $(n=24)$ reported adverse events. Major adverse events reported were respiratory symptoms (sore throat, cough, rhinorrhea and/or fever) and joint pain (knee, hip, shoulder or elbow). All adverse events were of mild intensity and judged by the medical investigator to be unrelated to the intervention. Furthermore, among the physical measurement parameters (body weight and BMI), physiological examinations (systolic and diastolic blood pressures and pulse rate) and laboratory tests (urinalysis, hematology and blood chemistry), BMI and some parameters in hematology and blood chemistry indicated marked changes (data not shown) during the intervention in a small number of subjects; however, these changes were within reference values. Based on these findings, it was concluded that ADE-containing food did not induce adverse events.

\section{Discussion}

In this randomized, double-blind, placebo-controlled clinical trial, the effects of oral administration of ADE were evaluated in subjects with knee discomfort associated with physical activity. The effectiveness of ADE was assessed primarily on the basis of the JOA and JKOM scores. The majority of
JOA criteria were improved from the baseline values in both groups. Subscale III (joint flexion/stiffness) was markedly improved in the ADE diet group compared with the placebo group at weeks 8 and 12 after the intervention. Notably, it has previously been reported that ADE extract promotes the repair of articular cartilage in a rabbit cartilage damaged model (8). Furthermore, cartilage defects have been reported to correlate with the disturbance of knee extension during the progression of OA $(21,22)$. Therefore, it may be speculated that the improvement of joint flexion/stiffness may be due to the potential of ADE to repair injured cartilage in the knee joint. Conversely, subscales I (pain/walking function) and II (pain/step-up and down function) of the JOA criteria increased in both the ADE and the placebo group during the intervention, and there was no significant difference between the two groups. The high scores in the placebo group may be due to the characteristics of these pain-associated subscales, which depend on self-reporting and subjective measurements. Subscale IV (swelling) did not significantly change during the intervention in the ADE or placebo group. This may be explained by the fact that no subjects participating in the present study exhibited swelling in knee joints, as evidenced by the high scores (full score of 10 points) at the baseline and during the intervention.

In the assessment of JKOM scores, the percentages of change from the baseline exhibited a greater decrease in the ADE diet group compared with the placebo group at 12 weeks in the subscales III (condition in daily life), IV (general activities) and $\mathrm{V}$ (health conditions). The questions for subscale III evaluate the ability to perform daily routines during the last few days, such as 'How difficult is ascending 
or descending stairs?' and 'How long can you walk on a flat surface without taking a rest?'. The questions for subscale IV evaluate the general activities over the previous month, such as 'Have you gone to an event or to a department store during the last month?' and 'Were things that you usually do (some kind of lesson and meeting friends) difficult because of knee pain during the last month?'. The questions for subscale $\mathrm{V}$ evaluate general health during the last month, such as 'Do you think your health during the last month has been average?' and 'Do you think that knee pain has been affecting your health badly during the last month?'. Thus, the current results suggest that an ADE-supplemented diet may improve the ability to perform daily routines, general activities and health conditions.

Furthermore, to evaluate the effects of ADE more clearly, subjects with minimal cartilage damage (K/L 0-I and $>75$ points of JOA criteria) were selected and analyzed. Magnetic resonance imaging classification previously demonstrated that irregularity and thinning but no defects were observed on the articular surface of the knee joint in subjects with $>75$ points of JOA criteria (23). The current results indicated that subscales II (pain and stiffness in knees) and IV (general activities) of the JKOM criteria were significantly improved in the ADE diet group at 8 weeks compared with the placebo group. In addition, the total score of JKOM was markedly improved at 8 weeks in the ADE diet group compared with the placebo group and continued to decrease until 12 weeks in the ADE diet group. As ADE improved both subscale II (pain and stiffness in knees) of JKOM and subscale II (flexion and stiffness) of JOA, an ADE diet may alleviate stiffness in subjects with physical activity-associated knee discomfort. In addition, it may improve the ability to perform general activities in these subjects.

It has previously been reported that biomarkers for cartilage metabolism, particularly type II collagen metabolism, may be used for evaluating the pathogenesis of joint destruction and monitoring structure-modifying agents or therapies (24). Type II collagen degradation biomarkers such as CTX-II, C1, 2C and C2C, were used to estimate the efficacy of chondroprotective agents, glucosamine $(25,26)$ and chondroitin sulfate (27). Furthermore, type II collagen synthesis biomarkers such as PIICP have been used alone or in combination with type II collagen degradation biomarkers (e.g., CTX-II and C2C) for the assessment of chondroprotective agents such as glucosamine (28-30). The current study used CTX-II and C2C as type II collagen degradation markers, PIICP as a type II collagen synthesis marker, and MMP-13 as a major collagen-degrading enzyme. In addition, the ratios of the synthesis and degradation of type II collagen (C2C/PIICP and CTX-II/PIICP) were analyzed. In the ADE diet group, the levels of PIICP increased markedly at week 8 compared with the placebo group. ADE has been reported to promote the repair of damaged cartilage (8) and enhance the synthesis of collagen in false aged model rats (7). Based on these findings, ADE may have enhanced the synthesis of collagen, especially type II collagen, in the subjects involved in the present study, as evidenced by the increase of PIICP, which is a type II collagen synthesis marker. Furthermore, the levels of MMP-13 were significantly reduced in both groups compared with the baseline; however the changes of MMP-13 levels from baseline were more substantially reduced at weeks 4, 8 and 12 in the ADE diet group compared with the placebo group, although the difference was not significant. It has been reported that MMP-13 may be induced by inflammatory cytokines (18), whereas ADE exhibits an anti-inflammatory action on an arthritis model (7). Therefore, the anti-inflammatory action of ADE may be associated with the suppression of MMP-13. Together, these observations suggest that the chondroprotective and anti-inflammatory actions of ADE may contribute to improving knee joint function (as evidenced by subscale III of JOA and subscale II of JKOM), and general activities and QOL (as evidenced by subscale IV and total score of JKOM) in the subjects with mild knee discomfort.

In conclusion, in the current study, the administration of ADE-containing diet was confirmed to be safe and improved the scores concerning joint flexion and general activities in the subjects with mild knee discomfort. Notably, the management of knee discomfort is more effective at an early stage for maintaining knee function; thus, ADE could be a promising candidate as a functional food that is beneficial for joint health.

\section{Acknowledgements}

The authors would like to thank Professor Yamamoto (Total Technological Consultant Co., Ltd., Tokyo, Japan) for his valuable advice and support and Dr Nakagawa (Total Technological Consultant Co., Ltd.) for his statistical analysis of the data and preparation of the manuscript. This study was funded by Asahi Food \& Healthcare Company Ltd. (Tokyo, Japan). However, Asahi Food \& Healthcare did not have any role in the design and conduction of the study, subject recruitment, collection, management or analysis of the data.

\section{References}

1. Yoshimura N, Muraki S, Oka H, Mabuchi A, En-Yo Y, Yoshida M, Saika A, Yoshida H, Suzuki T, Yamamoto S, et al: Prevalence of knee osteoarthritis, lumbar spondylosis, and osteoporosis in Japanese men and women: The research on osteoarthritis/osteoporosis against disability study. J Bone Miner Metab 27: 620-628, 2009.

2. McAlindon TE, Bannuru RR, Sullivan MC, Arden NK, Berenbaum F, Bierma-Zeinstra SM, Hawker GA, Henrotin Y, Hunter DJ, Kawaguchi $\mathrm{H}$, et al: OARSI guidelines for the non-surgical management of knee osteoarthritis. Osteoarthritis Cartilage 22: 363-388, 2014.

3. $\mathrm{Xu} \mathrm{G}$ and Wang Q: Practical Illustrations of Chinese Materia Medica. Fujian Science \& Technology Publishing House. Fuzhou, pp92-93, 2006.

4. Ou M: Chinese-English Manual of Common-Used in Traditional Chinese Medicine. Joint Publishing (Hong Kong) Co., Ltd., Hong Kong, pp164-165, 1989.

5. Rashad S, Low F, Revell P, Hemingway A, Rainsford K and Walker F: Effect of non-steroidal anti-inflammatory drugs on course of osteoarthritis. Lancet 2: 1149, 1989.

6. Herman JH and Hess EV: Nonsteroidal anti-inflammatory drugs and modulation of cartilaginous changes in osteoarthritis and rheumatoid arthritis. Clinical implications. Am J Med 77: 16-25, 1984.

7. Ono Y, Fukaya Y, Imai S and Yamakuni T: Beneficial effects of Ajuga decumbens on osteoporosis and arthritis. Biol Pharm Bull 31: 1199-1204, 2008.

8. Sawada Y, Sugimoto A, Fukuda K, Osaki T and Minami S: Oral administration of Ajuga decumbens extract has a synergetic effect with glucosamine on cartilaginous injury in a rabbit osteoarthritis model. J Chitin Chitosan Sci 2: 191-196, 2014. 
9. Akai M, Iwaya T, Kurosawa H, Doi T, Nasu T, Hyashi K and Fujino K; JKOM (Japanese Knee Osteoarthritis Measure): Development of new disease-specific QOL measure for patients with knee osteoarthritis: Japanese Knee Osteoarthritis Measure (JKOM). J Physical Medicine 16: 55-62, 2005 (In Japanese).

10. Akai M, Doi T, Fujino K, Iwaya T, Kurosawa H and Nasu T: An outcome measure for Japanese people with knee osteoarthritis. J Rheumatol 32: 1524-1532, 2005.

11. Koshino T and Niwa J: Assessment criteria for knee diseases and treatments. J Jpn Orthop Assoc 62: 900-904, 1988 (In Japanese).

12. Kellgren JH and Lawrence JS: Radiological assessment of osteo-arthrosis. Ann Rheum Dis 16: 494-502, 1957.

13. Muraki S, Oka H, Akune T, Mabuchi A, En-yo Y, Yoshida M, Saika A, Suzuki T, Yoshida H, Ishibashi H, et al: Prevalence of radiographic knee osteoarthritis and its association with knee pain in the elderly of Japanese population-based cohorts: The ROAD study. Osteoarthritis Cartilage 17: 1137-1143, 2009.

14. Reijman M, Hazes JM, Bierma-Zeinstra SM, Koes BW, Christgau S, Christiansen C, Uitterlinden AG and Pols HA: A new marker for osteoarthritis: Cross-sectional and longitudinal approach. Arthritis Rheum 50: 2471-2478, 2004.

15. Poole AR, Ionescu M, Fitzcharles MA and Billinghurst RC: The assessment of cartilage degradation in vivo: Development of an immunoassay for the measurement in body fluids of type II collagen cleaved by collagenases. J Immunol Methods 294: 145-153, 2004.

16. Nelson F, Dahlberg L, Laverty S, Reiner A, Pidoux I, Ionescu M, Fraser GL, Brooks E, Tanzer M, Rosenberg LC, et al: Evidence for altered synthesis of type II collagen in patients with osteoarthritis. J Clin Invest 102: 2115-2125, 1998.

17. Wang S, Wei X, Zhou J, Zhang J, Li K, Chen Q, Terek R, Fleming BC, Goldring MB, Ehrlich MG, et al: Identification of $\alpha 2$-macroglobulin as a master inhibitor of cartilage-degrading factors that attenuates the progression of posttraumatic osteoarthritis. Arthritis Rheum 66: 1843-1853, 2014

18. Poole AR, Nelson F, Dahlberg L, Tchetina E, Kobayashi M, Yasuda T, Laverty S, Squires G, Kojima T, Wu W and Billinghurst RC: Proteolysis of the collagen fibril in osteoarthritis. Biochem Soc Symp 115-123, 2003.

19. Braham R, Dawson B and Goodman C: The effect of glucosamine supplementation on people experiencing regular knee pain. Br J Sports Med 37: 45-49, 2003.

20. Nagaoka I, Suzuki A, Kurokawa M, Tamonaga A, Fukagawa M, Watanabe $\mathrm{K}$ and Yamamoto T: Effect of a dietary supplement containing collagen peptide on symptoms and biomarkeres in individuals with knee pain. Glucosamine Res 9: 40-47, 2013 (In Japanese).
21. Watanabe H, Urabe K, Kamiya K, Hamazaki N, Miida K, Suda K, Hendona T, Fujita M, Aikawa J, Itoman $M$ and Futami T: Relationship between quality of life using the Japan Knee Osteoarthritis Measure (JKOM) and physical function in patients with osteoarthritis of the knee. Jpn Physical Therapy Association 34: 67-73, 2007 (In Japanese).

22. Watanabe H, Urabe K, Takahira N, Ikeda N, Fujita M, Obara S, Hendona T, Aikawa J and Itoman M: Quality of life, knee function, and physical activity in Japanese elderly women with early-stage knee osteoarthritis. J Orthop Surg (Hong Kong) 18: 31-34, 2010

23. Nozaki H, Takezawa Y, Suguro T, Igata L, Kudo Y and Motegi M: MRI of articular cartilaginous lesions: MRI findings in osteoarthritis of the knee joint. Jpn j rheum and joint surg 13: 341-352, 1994.

24. Garnero P and Delmas PD: Biomarkers in osteoarthritis. Curr Opin Rheumatol 15: 641-646, 2003.

25. Christgau S, Henrotin Y, Tankó LB, Rovati LC, Collette J, Bruyere O, Deroisy R and Reginster JY: Osteoarthritic patients with high cartilage turnover show increased responsiveness to the cartilage protecting effects of glucosamine sulphate. Clin Exp Rheumatol 22: 36-42, 2004.

26. Cibere J, Thorne A, Kopec JA, Singer J, Canvin J, Robinson DB, Pope J, Hong P, Grant E, Lobanok T, et al: Glucosamine sulfate and cartilage type II collagen degradation in patients with knee osteoarthritis: Randomized discontinuation trial results employing biomarkers. J Rheumatol 32: 896-902, 2005.

27. Mazieres B, Hucher M, Zaïm M and Garnero P: Effect of chondroitin sulphate in symptomatic knee osteoarthritis: A multicentre, randomised, double-blind, placebo-controlled study. Ann Rheum Dis 66: 639-645, 2007.

28. Yoshimura M, Sakamoto K, Tsuruta A, Yamamoto T, Ishida K, Yamaguchi H and Nagaoka I: Evaluation of the effect of glucosamine administration on biomarkers for cartilage and bone metabolism in soccer players. Int J Mol Med 24: 487-494, 2009.

29. Momomura R, Naito K, Igarashi M, Watari T, Terakado A, Oike S, Sakamoto K, Nagaoka I and Kaneko K: Evaluation of the effect of glucosamine administration on biomarkers of cartilage and bone metabolism in bicycle racers. Mol Med Rep 7: 742-746.2013.

30. Nagaoka I: Recent Aspects of the chondroprotective and anti-inflammatory actions of glucosamine, a functional food. Juntendo Med J 60: 580-587, 2014 